\title{
Adsorption Behavior of Divalent Metal Ions onto Surface-functionalized Mesoporous Silicate MCM-41 Having Schiff Base Structure
}

\author{
Syunichi Oshima, ${ }^{* 1 \dagger}$ Hidekazu OHINata, ${ }^{* 2}$ Takushi Matsuno, ${ }^{* 1}$ Kenta Takasawa, ${ }^{* 1}$ \\ Yujiro Watanabe, ${ }^{* 3}$ Kaoru Fujinaga, ${ }^{* 1}$ Geoffrey W. Stevens, ${ }^{* 4}$ and Yu Komatsu ${ }^{* 1}$ \\ *1 College of Bioscience and Chemistry, Kanazawa Institute of Technology, Ishikawa 921-8501, Japan \\ *2 Technology Planning Div., Nomura Micro Science Co., Ltd., Kanagawa 243-0021, Japan \\ *3 Faculty of Bioscience and Applied Chemistry, Hosei University, Tokyo 184-8584, Japan \\ *4 Department of Chemical Engineering, The University of Melbourne, Victoria 3010, Australia
}

\begin{abstract}
Surface functionalized mesoporous silicates, MCM-41s, having 3-(2-pyridylmethylideneimino)propyl group (PI-MCM-41) or 3-(2-quinolylmethylideneimino)propyl group (QI-MCM-41) were prepared via Schiff base reaction, and the adsorption behavior of metal ions onto the modified MCM-41s was investigated. The function groups on the modified MCM-41 surface were confirmed by Fourier transform infrared spectroscopy (FT-IR), X-ray photoelectron spectroscopy (XPS), and elemental analysis. The metal ions examined, $\mathrm{Co}^{2+}, \mathrm{Ni}^{2+}, \mathrm{Cu}^{2+}, \mathrm{Zn}^{2+}, \mathrm{Cd}^{2+}$, and $\mathrm{Pb}^{2+}$, were quantitatively adsorbed on the PI-MCM-41 and QI-MCM-41, except for $\mathrm{Mn}^{2+}$. In the complexation with these metal ions, it was suggested that imine-N and heterocyclic-N atoms act as donor atoms. In addition, it was considered that the hydrophobicity derived from the organo-functional groups modified on MCM-41 contributed to improving the adsorption ability.
\end{abstract}

Keywords Mesoporous silicate, functionalized MCM-41, Schiff base, adsorption of metal ions

(Received March 11, 2020; Accepted October 12, 2020; Advance Publication Released Online by J-STAGE October 23, 2020)

\section{Introduction}

Mesoporous silicates are widely used as catalysts, adsorbents for large molecules, and supports for reactants. MCM-41 is one of the mesoporous silicates that has hexagonally packed arrays of one-dimensional, cylindrical pores, with a uniform pore distribution, large specific surface area, and large pore volume. ${ }^{1}$ Due to the large specific surface area of MCM-41, organofunctionalized surface modified MCM-41s have been used for immobilization of metals in catalyst fields..$^{2-4}$ A Schiff base has often been used to functionalize the modified MCM-41.5,6 Examples of modified MCM-41 with 3-(2-pyridylmethylideneimino)propyl and 3-(2-quinolylmethylideneimino)propyl groups as Schiff base structure have been synthesized and their thermal properties and catalytic activity evaluated. ${ }^{7,8}$

The organo-functionalized modified MCM-41 has the potential to be used as support for supra-molecular ligands used in the complexation of metal ions, ${ }^{9}$ and has also been used as fluorescent material for the detection of $\mathrm{Be}^{2+} \cdot{ }^{10}$ Furthermore, adsorption of metal ions on modified mesoporous silicate having functional groups such as thiol, ${ }^{11-15}$ amino, ${ }^{16-20}$ 2-(3-(2-aminoethylthio)propylthio)ethanamine, ${ }^{21}$ carboxy, ${ }^{22}$ iminodiacetic acid, ${ }^{23}$ EDTA, ${ }^{24}$ aniline, ${ }^{25}$ benzoylthiourea, ${ }^{26}$ 2-mercaptopyridine, ${ }^{27}$ 2-mercaptothiazoline, ${ }^{28}$ 5-mercapto-1-methyltetrazol, ${ }^{29}$ or phosphoryl,,$^{30}$ has been reported. In addition, the large

† To whom correspondence should be addressed.

E-mail: s.oshima@neptune.kanazawa-it.ac.jp specific surface area, which can be functionalized, leads to an increase in the potential adsorption capacity of metal ions. ${ }^{11}$

In this study, the adsorption behavior of metal ions on surfacefunctionalized mesoporous silicate MCM-41s having Schiff base structure was investigated. We focused on the 3-(2-pyridylmethylideneimino)propyl and 3-(2-quinolylmethylideneimino)propyl groups as functional groups based on our knowledge of the structural effects of chelate reagents in solvent extraction systems. As a result, we developed metal ion adsorbents, which have a similar structure to $N, N^{\prime}$-bis(2-pyridylmethylidene)-1,2diiminoethane (BPIE) ${ }^{31}$ and $N, N^{\prime}$-bis(2-quinolylmethylidene)1,2-diiminoethane (BQIE), ${ }^{32}$ which reflected the structural effects in solvent extraction systems. In addition, by using MCM-41 as a support, the large surface area allowed for an increased number of modified sites compared to other silicate compounds. ${ }^{33,34}$ The surface of MCM-41 was modified with 3-aminopropyltriethoxysilane or 3-(2-aminoethylamino)propyltrimethoxysilane and these MCM-41s having amino groups are referred to as AP-MCM-41 (AP- = 3-aminopropyl-) and AA-MCM-41 (3-(2-aminoethylamino)propyl-), respectively. Subsequently, the modified MCM-41s having Schiff base structure, PI-MCM-41 (PI- = 3-(2-pyridylmethylideneimino) propyl-), was obtained by Schiff base reaction with amino groups in AP-MCM-41 using 2-pyridinecarboxaldehyde. Moreover, $n$-PI-MCM-41 ( $n$ shows position number of pyridyl group, and is 3 or 4), QI-MCM-41 (QI- = 3-(2-quinolylmethylideneimino)propyl-), BI-MCM-41 (BI- = 3-(phenylmethylideneimino)propyl-), and CI-MCM-41 (CI- = 3-(cyclohexylmethylideneimino)propyl-) were synthesized by Schiff base 


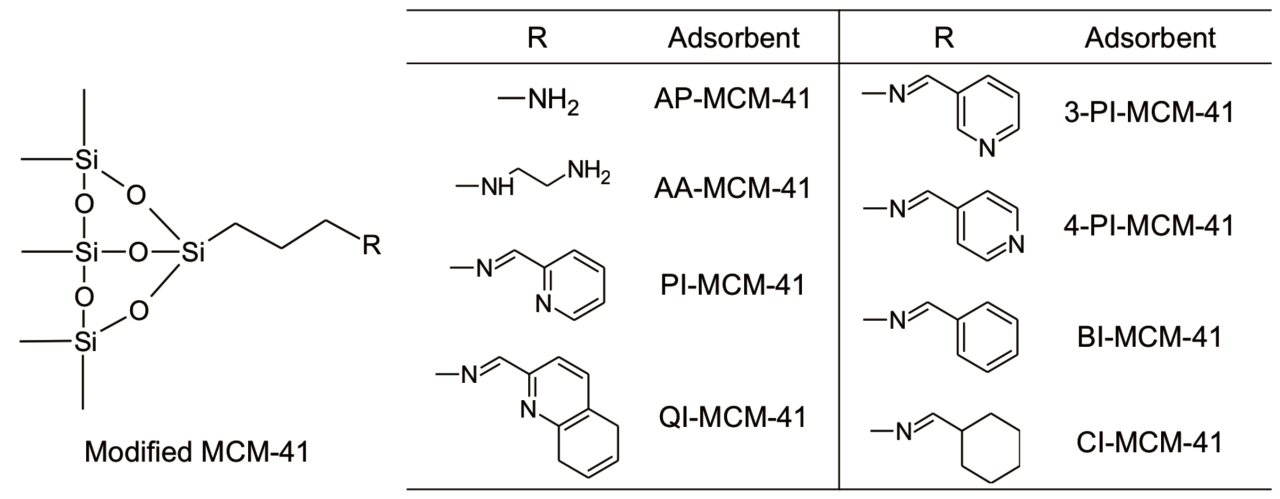

Fig. 1 Chemical structure of the modified MCM-41s.

reaction using a corresponding carbonyl compound in order to investigate the effect of the modified functional groups. The surface structure of the modified MCM-41s is shown in Fig. 1. These materials were characterized using X-ray diffraction (XRD) analysis, Fourier transform infrared spectroscopy (FTIR), X-ray photoelectron spectroscopy (XPS), nitrogen gas sorption, and elemental analysis. Adsorption behavior of metal ions onto the adsorbents was investigated as a function of $\mathrm{pH}$ in aqueous solution.

\section{Experimental}

\section{Apparatus}

Samples of the silicate product were characterized by powder $\mathrm{X}$-ray diffraction (XRD; RIGAKU, Ultima IV) using $\mathrm{Cu} K \alpha$ radiation and X-ray photoelectron spectroscopy (XPS; SHIMADZU, AXIS ULTRA). The $\mathrm{N}_{2}$ adsorption and desorption isotherm data for the samples was determined using a BELSORP 18 apparatus (BEL Japan, Inc.). Prior to nitrogen adsorption, the sample was degassed overnight. The infrared absorption spectra were obtained by FT-IR (JASCO, FT/IR-680 Plus) in the range of 4000 to $400 \mathrm{~cm}^{-1}$. The amount of organofunctional groups on modified MCM-41s was determined by elemental analysis on nitrogen. A HORIBA F-21 pH meter with a combination glass electrode was used to determine the $\mathrm{pH}$ values. An atomic absorption spectrometer (AAS; VARIAN, Spectra AA 220FS) or inductively coupled plasma optical emission spectrometer (ICP-OES; VARIAN, VISTA-PRO) was used for the determination of the concentration of metal ions in aqueous solution.

\section{Reagents and chemicals}

Cethyltrimethylammonium bromide (CTAB) and sodium silicate solution $\left(\sim 27 \% \mathrm{SiO}_{2}\right)$ were purchased from SigmaAldrich and used without the purification. 3-Aminopropyltriethoxysilane (Shin-Etsu Chemical Co., Ltd.) and 3-(2-aminoethylamino)propyltrimethoxysilane (Tokyo Chemical Industries, Ltd.) were used as silane coupling agents. 2-Pyridinecarboxaldehyde, 3-pyridinecarboxaldehyde, 4-pyridinecarboxaldehyde, 2-quinolinecarboxaldehyde, cyclohexanecarboxaldehyde (Tokyo Chemical Industry Co., Ltd.), and benzaldehyde (Wako Pure Chemical Industries, Ltd.) as carbonyl compounds were used after purification. All other chemicals were reagent-grade materials and Milli-Q water was used throughout.
Preparation of surface-functionalized MCM-41 having Schiff base structure

The synthesis of mesoporous silicate MCM-41 was performed by the previously reported method except for removal of CTAB. ${ }^{35}$ The obtained silicate product containing CTAB was added to $5 \mathrm{~mol} \mathrm{~L}^{-1}$ hydrochloric acid-methanol solution (20:80, $\mathrm{v} / \mathrm{v})$ and the mixture was stirred for $24 \mathrm{~h}$ at $40^{\circ} \mathrm{C}$ to extract CTAB. Then, the solid phase was recovered from solution by filtration, washed with ethanol, and dried under vacuum.

AP-MCM-41 having aminopropyl groups was prepared. One gram of MCM-41 was added to $200 \mathrm{~mL}$ of absolute toluene, and $4 \mathrm{mmol}$ of 3 -aminopropyltriethoxysilane was dropped. The mixture was refluxed for $6 \mathrm{~h}$ at $100^{\circ} \mathrm{C}$ under nitrogen atmosphere, and then $20 \mathrm{~mL}$ of ethanol as reaction terminator was added. After filtration, the obtained solid was washed with absolute toluene, and dried under vacuum. The unreacted materials were removed by Soxhlet extraction with $50 \mathrm{~mL}$ of dichloromethane and $50 \mathrm{~mL}$ of diethyl ether at $55^{\circ} \mathrm{C}$ for $6 \mathrm{~h}$ under nitrogen atmosphere and dried under vacuum. AA-MCM-41 having two amine nitrogen atoms was also prepared by the same manner described above.

The modified MCM-41 was synthesized via Schiff base reaction with each carbonyl compound. In a flask, $1 \mathrm{~g}$ of APMCM-41 was prepared and $100 \mathrm{~mL}$ of ethanol was added. Then, 2-pyridinecarboxaldehyde or other carbonyl compound (3 mmol) was added to the suspension with stirring at $25^{\circ} \mathrm{C}$. After $24 \mathrm{~h}$, the solid was recovered by filtration, washed with ethanol, and dried under vacuum.

\section{Adsorption of metal ions onto the modified MCM-41s}

The adsorption behavior for metal ions onto the modified MCM-41s was investigated as follows. The modified MCM-41 $(0.1 \mathrm{~g})$ was placed in a centrifuge tube and mixed with an aqueous phase $(10 \mathrm{~mL})$ containing $0.1 \mathrm{mmol} \mathrm{L}^{-1}$ of metal ion $\left(\mathrm{Mn}^{2+}, \mathrm{Co}^{2+}, \mathrm{Ni}^{2+}, \mathrm{Cu}^{2+}, \mathrm{Zn}^{2+}, \mathrm{Cd}^{2+}\right.$, or $\left.\mathrm{Pb}^{2+}\right), 0.1 \mathrm{~mol} \mathrm{~L}^{-1}$ of ionic strength agent $\left(\mathrm{NaCl}\right.$ or $\left.\mathrm{KNO}_{3}\right)$, and $0.01 \mathrm{~mol} \mathrm{~L}^{-1}$ of buffer (chloroacetic acid, acetic acid or 2-( $N$-morpholino)ethanesulfonic acid) that had no influence on the adsorption. The mixture was agitated at $25^{\circ} \mathrm{C}$ for $3 \mathrm{~h}$ (the adsorption was equilibrated within $3 \mathrm{~h}$ ) and then the solid and aqueous phases were separated by filtration. The equilibrated $\mathrm{pH}$ of the aqueous phase and the concentration of metal ions in the aqueous phase were determined. The amount of metal ion adsorbed on the modified MCM-41 was calculated by subtracting the measured concentration with the initial concentration of metal ion in the aqueous phase, and the adsorption ratio (\%) was calculated. Moreover, in order to obtain the adsorption isotherms for 


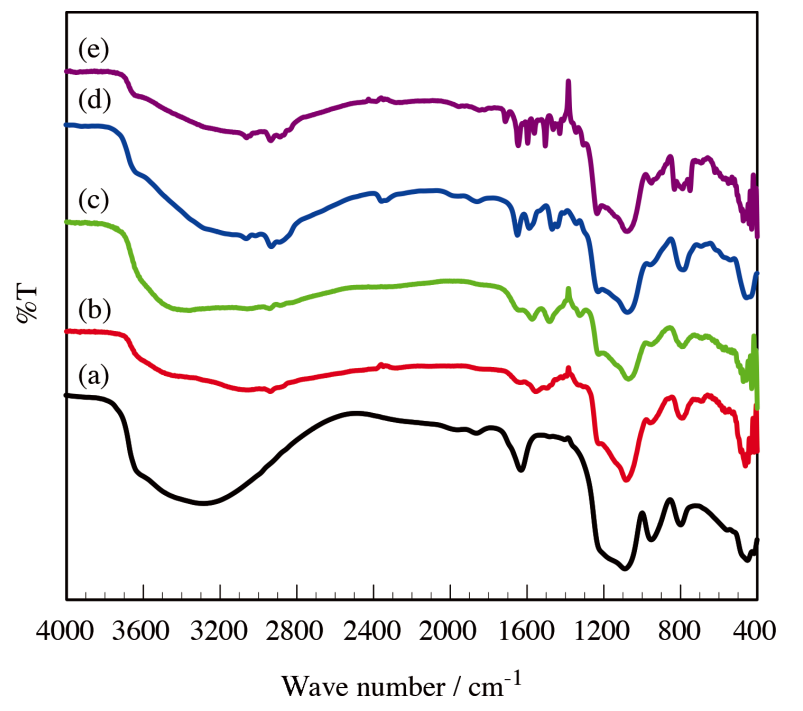

Fig. 2 FT-IR spectra of (a) MCM-41, (b) AP-MCM-41, (c) AAMCM-41, (d) PI-MCM-41, and (e) QI-MCM-41.

PI-MCM-41 and QI-MCM-41, the equilibrium $\mathrm{pH}$ was set to 2.7 and the initial concentration of $\mathrm{Cu}^{2+}$ in the aqueous phase was varied from $10^{-5}$ to $10^{-2} \mathrm{~mol} \mathrm{\textrm {L } ^ { - 1 }}$ at $25^{\circ} \mathrm{C}$.

\section{Results and Discussion}

\section{Characterization of the synthesized MCM-41s}

The IR spectra of the synthesized MCM-41s are shown in Fig. 2. In IR spectra, the peak of $\mathrm{Si}-\mathrm{O}-\mathrm{Si}$ in the MCM-41 structure and the broad peak of $\mathrm{O}-\mathrm{H}$ that originated from the silanol groups were observed at around $1085 \mathrm{~cm}^{-1}$ and $3000-3200 \mathrm{~cm}^{-1}$, respectively. In the spectra of modified MCM-41s, the peaks from the $\mathrm{C}-\mathrm{H}$ stretching and $\mathrm{N}-\mathrm{H}$ bending vibration in the aminopropyl groups were observed at around 2928 and $1560 \mathrm{~cm}^{-1}$, respectively. Furthermore, in the spectra of PI-MCM-41 and QI-MCM-41, the peak of C-H stretching vibration in pyridyl or quinolyl groups was observed at $3062 \mathrm{~cm}^{-1}$, and $\mathrm{C}=\mathrm{N}$ stretching vibration in imino group or $\mathrm{C}=\mathrm{C}$ stretching vibration in the heterocyclic ring were observed at $1460-1650 \mathrm{~cm}^{-1}$. The wide-scan XPS spectra of MCM-41, AP-MCM-41, and PI-MCM-41 are shown in Fig. S1 (Supporting Information). In the XPS spectra of AP-MCM-41 and PIMCM-41, the peak of nitrogen atom was observed at $400 \mathrm{eV}$. In addition, the broad peaks of $\mathrm{C} 1 \mathrm{~s}$ and N1s with different half widths were obtained in the narrow-scan XPS spectra of APMCM-41 and PI-MCM-41, which means that there are multitype carbon and nitrogen bonds in the chemical structures of AP-MCM-41 and PI-MCM-41 (see Fig. S1).

The three peaks in the XRD pattern for each modified MCM41 identified at low angles $\left(2-8^{\circ}, 2 \theta\right)$ are a good indication of the ordered hexagonally arranged pore structure typical of MCM-41, although the intensity of peaks in the XRD pattern decreased after the modification, which means that crystalline was lowered by the modification. ${ }^{8}$

The structure properties of synthesized MCM-41 obtained by $\mathrm{N}_{2}$ adsorption and desorption measurements are summarized in Table 1 , which include $d_{100}$ spacing values, the hexagonal unit cell parameter $a_{0}$, and the amounts of functional groups by elemental analysis of nitrogen in AP-MCM-41, AA-MCM-41, PI-MCM-41, and QI-MCM-41. Some differences in these
Table 1 Structural properties of synthesized MCM-41, AP-MCM-41, AA-MCM-41, PI-MCM-41, and QI-MCM-41 ( $a_{0}$, $d_{100}$, specific surface area, pore diameter, pore volume) and amounts of the functional groups

\begin{tabular}{lcccccc}
\hline & $\begin{array}{c}\text { Specific } \\
\text { surface } \\
\text { area/ } \\
\mathrm{m}^{2} \mathrm{~g}^{-1}\end{array}$ & $\begin{array}{c}\text { Pore } \\
\text { diameter/ volume/ } \\
\mathrm{nm}\end{array}$ & $\begin{array}{c}\text { Pore } \\
\mathrm{cm}^{3} \mathrm{~g}^{-1}\end{array}$ & $\begin{array}{c}d_{100} / \\
\mathrm{nm}\end{array}$ & $\begin{array}{c}a_{0} \text { a/ } \\
\mathrm{nm}\end{array}$ & $\begin{array}{c}\text { Amount of } \\
\text { the functional } \\
\text { groups/ } \\
\mathrm{mmol} \mathrm{g}^{-1}\end{array}$ \\
\hline MCM-41 & $1.24 \times 10^{3}$ & 2.42 & 1.36 & 4.02 & 4.64 & - \\
AP-MCM-41 & $6.92 \times 10^{2}$ & 2.42 & 0.48 & 4.02 & 4.64 & 2.8 \\
AA-MCM-41 & $4.50 \times 10^{2}$ & 2.42 & 0.54 & 3.94 & 4.55 & 2.2 \\
PI-MCM-41 & $5.46 \times 10^{2}$ & 2.42 & 0.43 & 4.02 & 4.64 & 2.0 \\
QI-MCM-41 & $6.54 \times 10^{2}$ & 2.42 & 0.44 & 4.21 & 4.86 & 1.7 \\
\hline
\end{tabular}
a. $a_{0}=\frac{2}{\sqrt{3}} d_{100}$.

structural properties were observed due to differences in the synthesis lots.

Adsorption behavior for metal ions on the modified MCM-41s

The calculated adsorption ratios onto the modified MCM-41 were plotted as a function of the equilibrated $\mathrm{pH}$ in Fig. 3. The adsorption experiments suggested that the agitation at $\mathrm{pH} 3$ for $3 \mathrm{~h}$ results in some degradation of the modified functional groups within the first hour. However, the decomposition of the functional groups was not significant up to $5 \mathrm{~h}$ of agitation time and the decomposition did not occur in the neutral region. Therefore, the decomposition of the modified functional groups is expected to have little effect on the adsorption ability under the condition of this study. All the metal ions examined, with the exception of $\mathrm{Mn}^{2+}$ were adsorbed on AA-MCM-41, although only $\mathrm{Zn}^{2+}$ was adsorbed on AP-MCM-41. These results were the same as the study reported by Bois et al. ${ }^{11}$ If only the terminal amino- $\mathrm{N}$ atom in AA-MCM-41 acts as donor atom, it is considered that the adsorption behavior for AA-MCM-41 is almost the same as those for AP-MCM-41. However, the adsorption ability of AA-MCM-41 is much higher than that of AP-MCM-41. This fact is suggested to originated from the improved adsorption ability due to the formation of a chelate ring with metal ion using two amine- $\mathrm{N}$ as donor atoms, as previous reported. ${ }^{36,37}$ Moreover, all of the examined metal ions except for $\mathrm{Mn}^{2+}$ were quantitatively adsorbed on PI-MCM-41 and QI-MCM-41. The $\mathrm{pH}$ at which the adsorption ratio shows $50 \%$ is defined as $\mathrm{pH}_{1 / 2}$ and given in Table 2. The order of the reaction selectivity was $\mathrm{Cu}^{2+}>\mathrm{Zn}^{2+}>\mathrm{Ni}^{2+}>\mathrm{Co}^{2+} \approx \mathrm{Cd}^{2+}>$ $\mathrm{Pb}^{2+}>\mathrm{Mn}^{2+}$ for AA-MCM-41, $\mathrm{Cu}^{2+}>\mathrm{Ni}^{2+}>\mathrm{Cd}^{2+} \approx \mathrm{Co}^{2+}>$ $\mathrm{Zn}^{2+}>\mathrm{Pb}^{2+}>\mathrm{Mn}^{2+}$ for PI-MCM-41, and $\mathrm{Cu}^{2+}>\mathrm{Cd}^{2+} \approx \mathrm{Ni}^{2+}>$ $\mathrm{Zn}^{2+}>\mathrm{Co}^{2+}>\mathrm{Pb}^{2+}>\mathrm{Mn}^{2+}$ for QI-MCM-41. In addition, the adsorption behavior onto the modified MCM-41 was almost the same between the different lots. From the comparison of adsorption behavior between AA-MCM-41 and PI-MCM-41, it was found that the adsorption of metal ions for PI-MCM-41 has occurred in the more acidic region. In addition, the $\mathrm{pH}_{1 / 2}$ values, except for $\mathrm{Cu}^{2+}$ in QI-MCM-41, were larger than those in PI-MCM-41. It was considered that the formation of imine-Nmetal ions-heterocyclic-N chelate ring in QI-MCM-41 was less stable than that in PI-MCM-41 because of the weaker basicity of quinoline than that of pyridine. This change of the selectivity was almost the same as the change observed in solvent extraction systems between BPIE and BQIE having similar structures to PI-MCM-41 and QI-MCM-41. ${ }^{32}$ From these results, it was considered that the 3-(2-pyridylmethylideneimino)propyl and 


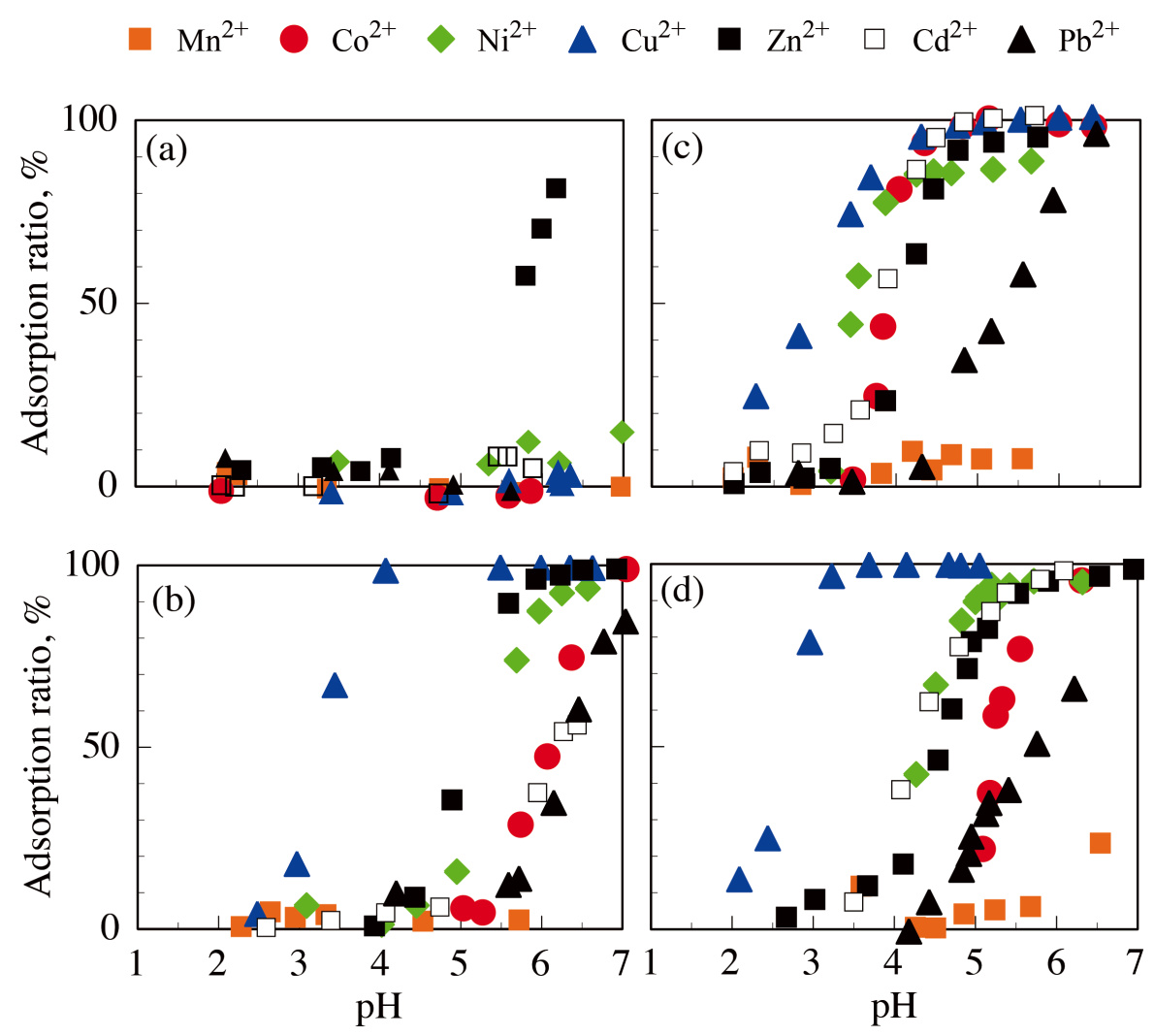

Fig. 3 Adsorption behavior for metal ions on (a) AP-MCM-14, (b) AA-MCM-41, (c) PI-MCM-41, and (d) QI-MCM-41.

Table 2 The $\mathrm{pH} 1 / 2$ values in AA-MCM-41, PI-MCM-41, and QI-MCM-41

\begin{tabular}{lccccccc}
\hline & $\mathrm{Mn}^{2+}$ & $\mathrm{Co}^{2+}$ & $\mathrm{Ni}^{2+}$ & $\mathrm{Cu}^{2+}$ & $\mathrm{Zn}^{2+}$ & $\mathrm{Cd}^{2+}$ & $\mathrm{Pb}^{2+}$ \\
\hline AA-MCM-41 & n.a. $^{a}$ & 6.1 & 5.4 & 3.3 & 5.1 & 6.2 & 6.3 \\
PI-MCM-41 & n.a. $^{a}$ & 3.9 & 3.5 & 3.0 & 4.1 & 3.8 & 5.4 \\
QI-MCM-41 & n.a. $^{a}$ & 5.2 & 4.3 & 2.7 & 4.6 & 4.1 & 5.7 \\
\hline
\end{tabular}

a. Not adsorption.

3-(2-quinolylmethylideneimino)propyl groups in PI-MCM-41 and QI-MCM-41 act as a bidentate ligand during complexation and the water molecules remained in the resulting metal complex. The complexes in PI-MCM-41 and QI-MCM-41 are more hydrophobic than that in AA-MCM-41 due to the presence of pyridyl and quinolyl groups. That is, it was considered that the pyridyl and quinolyl groups contributed to improve the hydrophobicity of the resulting complex and resulted in the improvement of adsorption ability in PI-MCM-41 and QIMCM-41. This is similar to the effect in solvent extraction systems using BPIE and its analogues. ${ }^{38}$ For $\mathrm{Cu}^{2+}$, it is considered that the high affinity of nitrogen atoms and the high hydrophobicity of the quinoline ring has improved the adsorption ability in QI-MCM-41.

The adsorption isotherms and Langmuir plots of $\mathrm{Cu}^{2+}$ on PI-MCM-41 and QI-MCM-41 are shown in Figs. S3 and S4, respectively. From these figures, it was found that the adsorption on the modified MCM-41 was of Langmuir type. Therefore, it was suggested that strong adsorption sites existed in the modified MCM-41 and metal ions formed the complex with the modified functional groups. The squared values $R^{2}$ of the correlation coefficient were 0.9973 for PI-MCM-14 and 0.9950 for QI-MCM-41. It was found that the saturated adsorption capacity was $2.1 \mathrm{mg} \mathrm{g}^{-1}$ for PI-MCM-41 and $2.1 \mathrm{mg} \mathrm{g}^{-1}$ for QI-MCM-41.

Using the modified MCM-41 with a change in the position and presence of the nitrogen atoms, we evaluated which nitrogen atoms act as donor atoms for the adsorption reaction of $\mathrm{Cu}^{2+}$. The adsorption behavior of $\mathrm{Cu}^{2+}$ onto various modified MCM41 is shown in Fig. 4. The complexation ability is low for 3-PIMCM-41, 4-PI-MCM-41, BI-MCM-41, and CI-MCM-41, which cannot form the chelate ring with metal ions. These results supported the hypothesis described above, and it was suggested that imine- $\mathrm{N}$ and heterocyclic- $\mathrm{N}$ atoms act as donor atoms in complexation with metal ions for PI-MCM-41 and QIMCM-41, as suggested in previous reports. ${ }^{7,8}$ In addition, it seems that the increase of hydrophobicity of the metal complex, which originated from the presence of pyridyl, phenyl, or cyclohexyl groups, improved the adsorption ability for metal ions in $n$-PI-MCM-41, BI-MCM-41, or CI-MCM-41 compared to AP-MCM-41.

In this adsorption reaction, it is necessary for neutralization of the metal ion charge after complexation with functional groups in PI-MCM-41 and QI-MCM-41, since imine-N, pyridine-N, and quinoline- $\mathrm{N}$ atoms act as neutral donor atoms. Thus, the adsorption behavior of $\mathrm{Cu}^{2+}$ and $\mathrm{Cd}^{2+}$ was investigated by changing the concentration of the ionic strength and the chemical species $\left(\mathrm{Cl}^{-}, \mathrm{NO}_{3}^{-}\right.$, or $\left.\mathrm{ClO}_{4}^{-}\right)$, which acts as a counter ion. It was found that the concentration of anions had little influence for adsorption, and it was suggested that the anionic species may affect the adsorption of metal ions slightly as shown in Fig. S5. From the results, it was considered that the charge of the complex for PI-MCM-41 and QI-MCM-41 during 


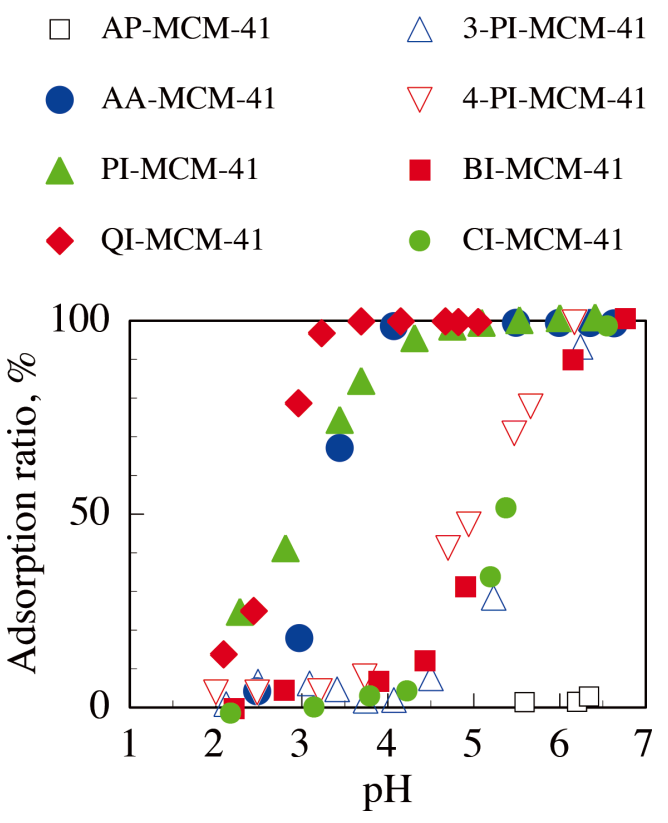

Fig. 4 Adsorption behavior of copper ion on various modified MCM-41s.

adsorption of metal ions was neutralized by appropriate counter anions present in the aqueous phase. . $^{8,37}$

In summary, it was found that PI-MCM-41 and QI-MCM-41 show adsorption characteristics that reflect the structural effects of the modifying ligands, although the adsorption capacity is lower than commercially available adsorbents.

\section{Supporting Information}

Additional data, including wide-scan and narrow-scan XPS spectra, XPS patterns for modified MCM-41s, the adsorption isotherms and Langmuir plots, and the effect of counter anion species are given as Supporting Information. This material is available free charge on the Web at http://www.jsac.or.jp/ analsci/.

\section{References}

1. C. T. Kresge, M. E. Leonowicz, W. J. Roth, J. C. Vartuli, and J. S. Beck, Nature, 1992, 359, 710.

2. S.-H. Lau, V. Caps, K.-W. Yeung, K.-Y. Wong, and S. C. Tsang, Microporous Mesoporous Mater., 1999, 32, 279.

3. S. Shylesh and A. P. Singh, J. Catal., 2006, 244, 52.

4. T. Joseph, K. V. Kumar, A. V. Ramaswamy, and S. B. Halligudi, Catal. Commun., 2007, 8, 629.

5. M. Masteri-Farahani, F. Farzaneh, and M. Ghandi, J. Mol. Catal. A: Chem., 2006, 248, 53.

6. J. Gao, L. Lu, W. Zhou, G. Gao, and M. He, J. Porous Mater, 2008, 15, 127.

7. E. İspir and S. Serin, J. Therm. Anal. Calorim., 2008, 94, 281.

8. K. Komura, H. Nakamura, and Y. Sugi, J. Mol. Catal. A: Chem., 2008, 293, 72.

9. P. Mukherjee, S. Laha, D. Mandal, and R. Kumar, Stud. Surf. Sci. Catal., 2000, 129, 283.
10. X. Guan, D. Li, J. Song, Y. Ji, and F.-S. Xiao, J. Porous Mater., 2008, 15, 527.

11. L. Bois, A. Bonhommé, A. Ribes, B. Pais, G. Raffin, and F. Tessier, Colloids Surf. A, 2003, 221, 221.

12. J. Aguado, J. M. Arsuaga, and A. Arencibia, Ind. Eng. Chem. Res., 2005, 44, 3665.

13. Q. Yang, J. Liu, J. Yang, L. Zhang, Z. Feng, J. Zhang, and C. Li, Microporous Mesoporous Mater, 2005, 11, 257.

14. J. Aguado, J. M. Arsuaga, and A. Arencibia, Microporous Mesoporous Mater., 2008, 109, 513.

15. J. M. Arsuaga, J. Aguado, A. Arencibia, and M. S. LópezGutiérrez, Adsorption, 2014, 20, 311.

16. T. Yokoi, H. Yoshitake, and T. Tatsumi, J. Mater. Chem., 2004, 14, 951.

17. M. Algarra, M. V. Jiménez, E. Rodríguez-Castellón, A. Jiménez-Lópoz, and J. Jiménez-Jiménez, Chemosphere, 2005, 59, 779 .

18. K. F. Lam, K. L. Yeung, and G. Mckay, J. Phys. Chem. B, 2006, 110, 2187.

19. K. F. Lam, K. L. Yeung, and G. Mckay, Environ. Sci. Technol., 2007, 41, 3329.

20. H. W. Lee, H. J. Cho, J.-H. Yim, J. M. Kim, J.-K. Jeon, J. M. Sohn, K.-S. Yoo, S.-S. Kim, and Y.-K. Park, J. Ind. Eng. Chem., 2011, 17, 504.

21. M. Puanngam and F. Unob, J. Hazard. Mater., 2008, 154, 578.

22. K. F. Lam, K. L. Yeung, and G. Mckay, Microporous Mesoporous Mater., 2007, 100, 191.

23. R. He, Z. Wang, L. Tan, Y. Zhong, W. Li, D. Xing, D. Wei, and Y. Tang, Microporous Mesoporous Mater., 2018, 257, 212.

24. Y. Shiraishi, G. Nishimura, T. Hirai, and I. Komasawa, Ind. Eng. Chem. Res., 2002, 41, 5065.

25. F. A. Pavan, T. M. H. Costa, and E. V. Benvenutti, Colloids Surf. A, 2003, 226, 95.

26. V. Antochshuk, O. Olkhovyk, M. Jaroniec, I.-S. Park, and R. Ryoo, Langmuir, 2003, 19, 3031.

27. D. Pérez-Quintanilla, I. del Hierro, M. Fajardo, and I. Sierra, Mater. Res. Bull., 2007, 42, 1518.

28. D. Pérez-Quintanilla, I. del Hierro, M. Fajardo, and I. Sierra, J. Hazard. Mater., 2006, 134, 245.

29. D. Pérez-Quintanilla, A. Sánchez, I. del Hierro, M. Fajardo, and I. Sierra, J. Colloid Interface Sci., 2007, 313, 551.

30. X. Guo, Y. Feng, L. Ma, D. Gao, J. Jing, J. Yu, H. Sun, H. Gong, and Y. Zhang, Appl. Surf. Sci., 2017, 402, 53.

31. S. Oshima, N. Hirayama, K. Kubono, H. Kokusen, and T. Honjo, Anal. Chim. Acta, 2001, 441, 157.

32. S. Oshima, N. Hirayama, K. Kubono, H. Kokusen, and T. Honjo, Anal. Sci., 2002, 18, 1351.

33. S. Dai, M. C. Burleigh, Y. Shin, C. C. Morrow, C. E. Barnes, and Z. Xue, Angew. Chem. Int. Ed., 1999, 38, 1235.

34. S. Dai, M. C. Burleigh, Y. H. Ju, H. J. Gao, J. S. Lin, S. J. Pennycook, C. E. Barnes, and Z. L. Xue, J. Am. Chem. Soc., 2000, 122, 992.

35. S. Oshima, J. M. Perera, K. A. Northcott, H. Kokusen, G. W. Stevens, and Y. Komatsu, Sep. Sci. Technol., 2006, 41, 1635.

36. R. D. Makote and S. Dai, Anal. Chim. Acta, 2001, 435, 169.

37. S. Shimazu, N. Baba, N. Ichikuni, and T. Uematsu, J. Mol. Catal. A: Chem., 2002, 182-183, 343.

38. S. Oshima, N. Hirayama, K. Kubono, H. Kokusen, and T. Honjo, Talanta, 2003, 59, 867. 